\title{
Implementation and initial calibration of carbon-13 soil organic matter decomposition in Yasso model
}

\author{
Jarmo Mäkelä ${ }^{1}$, Laura Arppe ${ }^{2}$, Hannu Fritze ${ }^{3}$, Jussi Heinonsalo ${ }^{4}$, Jari Liski ${ }^{1}$, Markku Oinonen $^{2}$, \\ Petra Straková ${ }^{5}$, and Toni Viskari ${ }^{1}$ \\ ${ }^{1}$ Finnish Meteorological Institute, P.O. Box 503, FI-00101 Helsinki, Finland \\ ${ }^{2}$ Finnish Museum of Natural History LUOMUS, P.O. Box 64, 00014, University of Helsinki, Helsinki, Finland \\ ${ }^{3}$ Natural Resources Institute Finland, P.O. Box 18, FI-01301, Vantaa, Finland \\ ${ }^{4}$ Department of Microbiology and Institute for atmospheric research INAR, Faculty of Agriculture and Forestry, P.O. Box 56, \\ 00014 University of Helsinki, Helsinki, Finland \\ ${ }^{5}$ Natural Resources Institute Finland, P.O. Box 2, 00791, Helsinki, Finland
}

Correspondence: Jarmo Mäkelä (jarmo.makela@fmi.fi)

\begin{abstract}
Soil carbon sequestration has gained traction as a mean to mitigate rising atmospheric carbon dioxide concentrations. Verification of different methods' efficiency to increase soil carbon sink requires, in addition to good quality measurements, reliable models capable of simulating the effect of the sequestration practises. One way to get insight of the methods' effects on carbon cycling processes is to analyse different carbon isotope concentrations in soil organic matter. In this paper we introduce a carbon-13 isotope specific soil organic matter decomposition add-on into the Yasso soil carbon model and assess its functionality. The new ${ }^{13} \mathrm{C}$-dedicated decomposition is straightforward to implement and depends linearly on the default Yasso model parameters and the relative carbon isotope $\left({ }^{13} \mathrm{C} /{ }^{12} \mathrm{C}\right)$ concentration. Despite of their simplicity, the modifications considerably improve the model behaviour in a 50-year long simulation.
\end{abstract}

\section{Introduction}

Soil carbon (C) sequestration has been a serious topic of interest for several decades as a promising method to mitigate the rising atmospheric carbon dioxide $\left(\mathrm{CO}_{2}\right)$ concentrations. These type of methods aim to increase the soil carbon sink by e.g. different soil tilling (Wilman, 2011), crop rotation (Acharya et al., 2012) or fertilisation practises (Triberti et al., 2016). The fundamental problem related to $\mathrm{C}$ sequestration is how to demonstrate that the proposed management practice and land use change increase soil $\mathrm{C}$ stock size, and under what conditions and for how long the $\mathrm{C}$ will remain in the soil.

The quantification of small changes in soil $\mathrm{C}$ stocks is challenging due to large natural variability in soils and the large standing $\mathrm{C}$ stock. It has been estimated that the detection of $0.1 \mathrm{~kg} \mathrm{C} \mathrm{m}^{-2}$ change (approx. 1\%) in an agricultural field in Finland where $\mathrm{C}$ stock size ranges between 8.4 and $9.8 \mathrm{~kg} \mathrm{~m}^{-2}$ in the top $30 \mathrm{~cm}$ requires hundreds of soil samples to be analyzed (Heikkinen et al., 2020). For this reason, an efficient verification system based on a combination of measurements (C stock size, $\mathrm{CO}_{2}$ exchange, remote sensing etc.) and modelling is required and a new global vision of MRV (Monitoring, Reporting, Verification) platform was proposed by Smith et al. (2020). 
It is essential to understand which soil processes are the most important for soil $\mathrm{C}$ sequestration. The soil $\mathrm{C}$ pool can be divided into different fractions based on their chemical composition, physical characteristics or assumed turnover or residence times (Poeplau et al., 2018). Soil processes in general are complex as biological, chemical and physical drivers act simultaneously. For modelling purposes, the fate of carbon-13 isotope $\left({ }^{13} \mathrm{C}\right)$ gives valuable additional information of the parameter values of used model as the ${ }^{13} \mathrm{C}$ signatures are sensitive indicators of changes in processes. Soil organic matter (SOM) consists of molecules with different carbon isotopes. In theory, molecules with lighter ${ }^{12} \mathrm{C}$ atoms have lower activation (kinetic) energy requirements than those with ${ }^{13} \mathrm{C}$. This leads to easier decomposition of ${ }^{12} \mathrm{C}$-bearing compounds and enrichment of ${ }^{13} \mathrm{C}$ in residual organic molecules (Fry, 2006). By estimating ${ }^{13} \mathrm{C}$ in different fractions of SOM or varying residence times and adding ${ }^{12} \mathrm{C} /{ }^{13} \mathrm{C}$ reaction kinetics into the models would allow verification of the model functioning, and improve model predictions.

${ }^{13} \mathrm{CO}_{2}$ measurements associated with gas flux measurements provide a promising way to link soil models to ecosystem models and allow further integration to earth system models where ${ }^{13} \mathrm{C}$ isotopes are used to detect large scale $\mathrm{C}$ cycling patterns (Flanagan et al., 2005).

There are a multitude of ways to improve MRV (Smith et al., 2020), but in our experience one method has not been as readily examined - that of carbon isotope composition in the soil and in heterotrophic respiration. The reason behind the lack of such examinations is simple, such approaches require a model that can reliably represent the soil organic carbon (SOC) dynamics for different carbon isotopes while still retaining relatively straightforward structure. The latter is especially important when we take into account the lack of good-quality calibration and validation data.

In this paper we introduce a simple ${ }^{13} \mathrm{C}$ isotopic circulation into the recently re-calibrated SOC model Yasso (Viskari et al., 2021, 2020; Tuomi et al., 2011). In our approach, the decomposition of ${ }^{13} \mathrm{C}$-specific soil organic matter $\left({ }^{13} \mathrm{C}\right.$-SOM) is linearly dependent on the default Yasso model parameters, the carbon isotope fraction ${ }^{13} \mathrm{C} /{ }^{12} \mathrm{C}$ and a new scaling factor $\theta$, that represents change to the decomposition rate between the carbon isotopes. The underlying hypothesis behind this design is that since ${ }^{13} \mathrm{C}$ has a larger atomic weight it is therefore not as reactive as ${ }^{12} \mathrm{C}$, but environmental factors should still affect the decomposition of SOM, containing either isotope, similarly. We calibrate the new ${ }^{13} \mathrm{C}$-related decomposition parameters $(\theta)$ and assess the model functionality both on short and long term (50-year simulation) basis.

Our aim is to improve Yasso20 model parameterisation (Viskari et al., 2021) to include ${ }^{13} \mathrm{C} /{ }^{12} \mathrm{C}$ reaction kinetics in the model by using empirically measured SOM and ${ }^{13} \mathrm{C}$ data. We hypothesize that measuring ${ }^{13} \mathrm{C}$ in soil organic matter fractions 1) detects differences in the pool ${ }^{13} \mathrm{C}$ content supporting the ${ }^{13} \mathrm{C}$-fractionation and enrichment theory, and 2) allows model development for significant improvements in SOM decomposition predictions.

\section{Materials and methods}

\subsection{Measurements}

The SOC measurements were derived from experiments described in Straková et al. (2012, 2011, 2010), where different types of plant litter was left to decompose inside litterbags in natural environment at Lakkasuo, a raised bog complex in Central Finland $\left(61.8^{\circ} \mathrm{N}, 24.3^{\circ} \mathrm{E}, 150\right.$ m.a.s.l.). We utilised data detailing the conditions for pine branch and pine needle specific 
https://doi.org/10.5194/bg-2021-327

Preprint. Discussion started: 23 December 2021

(c) Author(s) 2021. CC BY 4.0 License.

\section{(c) $\underset{\mathrm{BY}}{\mathrm{BV}}$}

litterbags. In addition to determining the initial states for both litter types, 14 litterbags describe the soil conditions for pine branches and seven for pine needles at later stages of decomposition during the four-year-long experiment.

The litter was characterized by dividing it into carbon fractions by sequential extractions and hydrolysis according to Hilasvuori et al. 2013 (and references therein), also called AWEN extraction (acid, water, ethanol, non-soluble). In short, this included analysing the amounts of nonpolar extracts (corresponds to E), polar extracts (W), acid hydrolysable substances (A) and non-soluble Klason type substances (N). Air dried litter material was ground in a mill (Fritsch) to pass the $0.5 \mathrm{~mm}$ sieve and weighted into a centrifuge tube $(35 \mathrm{ml})$. The amount of extractables was determined through the remaining mass after shaking ( $2 \mathrm{~h}$ or $18 \mathrm{~h} ; 250 \mathrm{rpm}$ ) with the different solvents followed by filtering through glass crucibles (Robu, Borosilicat 3.3 por. 4). At the start of the extraction procedure $0.5 \mathrm{~g}$ litter mass was used. Dichloromethane $\left(\mathrm{CH}_{2} \mathrm{Cl}_{2} ; 15 \mathrm{ml} ;\right.$ repeated twice $)$ was first used to remove the nonpolar extractives. $0.35 \mathrm{~g}$ of the remaining dried $\left(105^{\circ} \mathrm{C}\right)$ solid sample was weighted again into a centrifuge tube and hot water $\left(80^{\circ} \mathrm{C} ; 15 \mathrm{ml}\right)$ was added and kept in a water bath $\left(80{ }^{\circ} \mathrm{C} ; 18 \mathrm{~h}\right)$. After centrifugation $(1500 \times \mathrm{g})$ the pellet was washed with $30 \mathrm{ml}$ hot water to finish the extraction for polar extractives. In all cases the respective extractives were combined and dried. Evaporation was used for the nonpolar fraction and warming $\left(50{ }^{\circ} \mathrm{C}\right)$ followed by freeze drying was polar fraction. $0.1 \mathrm{~g}$ oven dried $\left(105^{\circ} \mathrm{C}\right)$ material from the residue left after the hot water extraction was weighted into a centrifugation tube and $1.25 \mathrm{ml} 72 \%$ sulphuric acid $\left(\mathrm{H}_{2} \mathrm{SO}_{4}\right)$ was added and shaken in room temperature (1 h; 250 $\mathrm{rpm})$. Thereafter $35 \mathrm{ml}$ water was added and incubated in a water bath $\left(95^{\circ} \mathrm{C} ; 18 \mathrm{~h}\right)$ followed by filtration. The remaining mass (Klason lignin) was washed once with hot water $\left(95^{\circ} \mathrm{C} ; 30-40 \mathrm{ml}\right)$ and the mass was dried o/n in $105^{\circ} \mathrm{C}$. Each fraction ie. the original litter, the solid remains after dichloromethane, water and acid extraction and from the evaporated nonpolar and polar extractants, subsamples were analysed for their relative ${ }^{13} \mathrm{C} /{ }^{12} \mathrm{C}$ ratios as $\delta^{13} \mathrm{C}$ values. The definition of $\delta^{13} \mathrm{C}$ is given below, where $\left(\frac{{ }^{13} \mathrm{C}}{{ }^{12} \mathrm{C}}\right)_{\text {standard }}=0.01123720$ is the Vienna Pee Dee Belemnite (Craig, 1957, VPDB).

$\delta^{13} \mathrm{C}=\left(\frac{\left(\frac{{ }^{13} \mathrm{C}}{{ }^{12} \mathrm{C}}\right)_{\text {sample }}}{\left(\frac{{ }^{13} \mathrm{C}}{{ }^{12} \mathrm{C}}\right)_{\text {standard }}}-1\right) \cdot 1000 \%$

The isotopic composition of carbon was measured on a NC2500 elemental analyzer coupled to a Thermo Scientific Delta V Plus isotope ratio mass spectrometer at the Laboratory of Chronology, Finnish Museum of Natural History. The raw isotope data were normalised with a multi-point calibration using certified isotopic reference materials (USGS-40, USGS-41, IAEA$\mathrm{CH} 3$ and IAEA-CH7). The mean measured (pre-normalization) $\delta^{13} \mathrm{C}$ values for calibration references were -26.52 for USGS$40,+36.19$ for USGS-41, -24.88 for IAEA-CH3, and -32.27 for IAEA-CH7, with an $\mathrm{r}^{2}$ of $>0.999$ between measured and expected values. Replicate analyses of quality control reference materials analysed alongside the unknowns indicate a $1 \sigma$ internal precision of $\leq 0.20$. For the purpose of model calibration, all samples were scaled to represent the same amount of original matter (we use 1000 mass units of original matter - the given $\mathrm{C}$ and ${ }^{13} \mathrm{C}$ values are in relation to this value).

The meteorological variables required to run the Yasso model were extracted from a nearby weather station measurements (Kolari et al., 2009), located at Hyytiälä $\left(61.85^{\circ} \mathrm{N}, 24.29^{\circ} \mathrm{E}, 180 \mathrm{~m}\right.$. a.s.1.). We gathered monthly temperature and annual 
https://doi.org/10.5194/bg-2021-327

Preprint. Discussion started: 23 December 2021

(c) Author(s) 2021. CC BY 4.0 License.

\section{(c) (1)}

precipitation from the beginning of year 2005 to the end of 2008. Additionally we calculated averaged monthly temperature and averaged annual precipitation from years 2000-2014 to be used in simulating long-term carbon decomposition.

\subsection{Yasso model}

We generate the soil carbon pools utilising the Yasso SOC model (Liski et al., 2005). The underlying model version is the Yasso20 (Viskari et al., 2021) with parameter values given in appendix Table A1. We have introduced a new ${ }^{13} \mathrm{C}$ specific decomposition into this model, which utilises new parameters $\left(\theta\right.$, explained below). When all $\theta \equiv 0$, both ${ }^{12} \mathrm{C}$ and ${ }^{13} \mathrm{C}$ use the same standard decomposition parameters, hence we call this model the default Yasso model and the new version, with optimised $\theta$ parameters, as Yasso-C13 or optimised Yasso, when we need to make a distinction. Otherwise both models are simply referred to as the Yasso model.

Yasso decomposes litter into different pools that represent acid, water and ethanol (A, W and E) soluble matter and a lignin-

like pool $(\mathrm{N})$, all the pools having different decomposition rates. The decomposed $\mathrm{C}$ is released back to the atmosphere as heterotrophic respiration, shifted between the AWEN pools or transferred to inactive humus $(\mathrm{H})$ pool. The model is driven with monthly temperature and annual precipitation. The SOC pool decomposition in the Yasso model can be represented by the following equation.

$x_{t}=M x_{t-1}+b_{t}$

The state vector $\left(x_{t}\right)$, representing the $\mathrm{C}$ content in AWENH pools at time $t$, is calculated by operating the state transition matrix $(M)$ on the state vector of the previous time step $\left(x_{t-1}\right)$ and adding litter input $\left(b_{t}\right)$, which in our simulations is set to zero (as we assume no litter is added into the litterbags after the beginning). The model initial state (in our simulations) is set to match the first measurements. The matrix $M$ determines the decomposition of SOM and the flow of carbon between the different pools and it is dependent on various parameters as well as temperature and precipitation. We introduce ${ }^{13} \mathrm{C}$ SOM decomposition into the Yasso model by adding separate ${ }^{13} \mathrm{C}$-specific storages for each AWENH pool and including an additional ${ }^{13} \mathrm{C}$-specific SOM decomposition step. The input data (essentially carbon content) is first separated into ${ }^{13} \mathrm{C}$-specific content and the rest, which we call ${ }^{12} \mathrm{C}$ although it also contains ${ }^{14} \mathrm{C}$. The Yasso model is first run normally with ${ }^{12} \mathrm{C}$ as in Eq. 2, which is followed by ${ }^{13} \mathrm{C}$ decomposition using a modified version of the state transition matrix $M$. We modified the diagonal elements of $M$ (these determine the SOM decomposition within each pool) by replacing the parameter $(\alpha)$ affecting the diagonal element with:

$\alpha^{\star}=\left(1+\frac{{ }^{13} \mathrm{C}}{{ }^{12} \mathrm{C}} \theta\right) \alpha$

Essentially, we include a dependency for the mass ratio of the carbon isotopes $\left({ }^{13} \mathrm{C} /{ }^{12} \mathrm{C}\right)$ as well as a free parameter $\theta$ for each AWEN pool separately. We didn't include a parameter for the humus pool $(\mathrm{H})$ as we did not have measurements to calibrate the related parameter. We also note here that the diagonal elements are further dependent on temperature and precipitation, but these model aspects were not modified. Further details on Yasso model can be found in Viskari et al. (2021). 
https://doi.org/10.5194/bg-2021-327

Preprint. Discussion started: 23 December 2021

(c) Author(s) 2021. CC BY 4.0 License.

\subsection{Model calibration}

We calibrated the four $\theta$ parameters related to the decomposition of each AWEN pool ${ }^{13} \mathrm{C}-\mathrm{SOM}$. The objective function $(f)$ of the calibration is the cumulative squared error of the observed and modelled $\delta^{13} \mathrm{C}$ values:

$f=\sum_{i}\left(\delta^{13} \mathrm{C}_{i, \text { modelled }}-\delta^{13} \mathrm{C}_{i, \text { observed }}\right)^{2}$.

Here the summation is taken over all AWEN pools and available litterbag measurements (with measurements indicating zero concentration for total carbon content removed from the calculations). The unnormalised (pointwise) parameter likelihood is calculated as $\mathcal{L}=e^{-f}$.

Since we had only four parameters to calibrate, we set similar initial limits for the parameters and a suitable increment that determined how densely the parameter values were distributed. We ran the model with every member of the parameter "grid" to get an estimate of the overall shape of the parameter likelihood and to test for reasonable limiting values for the parameters. This process was repeated several times with refocused grid and readjusted increment.
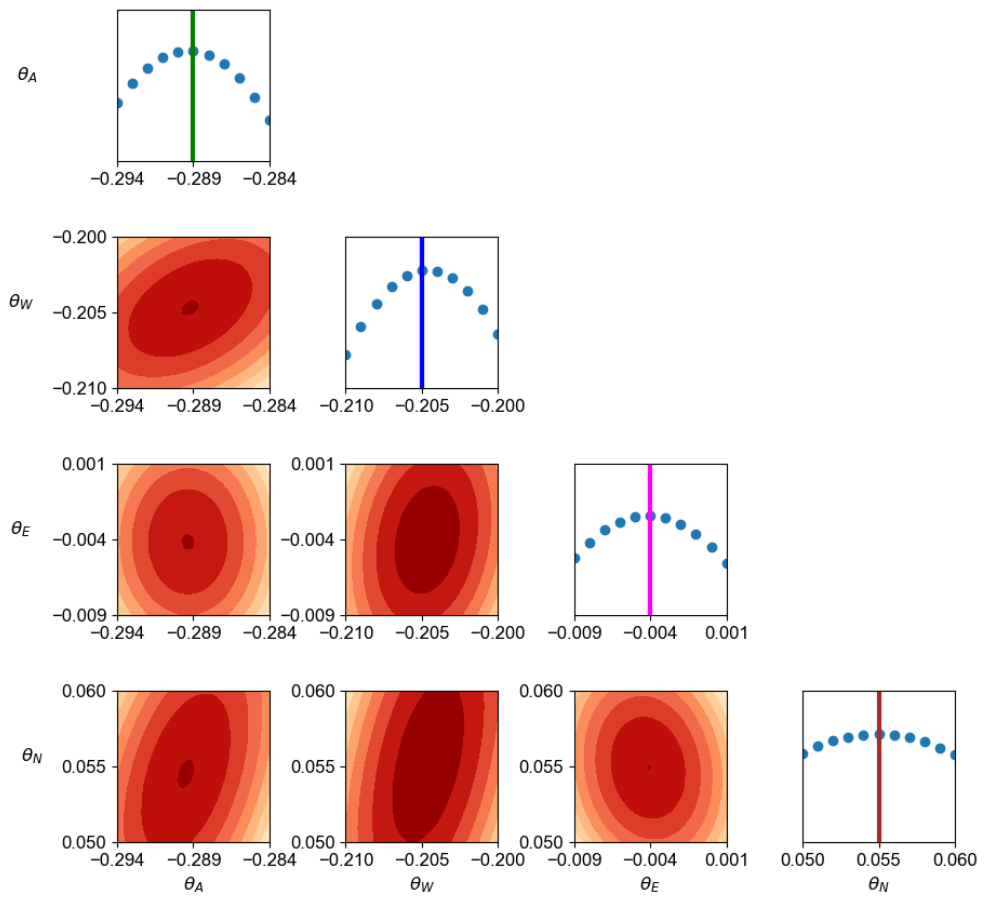

Figure 1. Presented are marginal likelihoods for each calibrated parameter as well as likelihood dependencies between each two parameters, calculated by setting the other parameters to their optimal values. 


\section{Results}

The Yasso model calibration resulted in strictly unimodal parameter probability distributions (Fig. 1). This was not unexpected as each calibrated parameter could only directly affect a single AWEN pool. The optimised parameter values are $\theta_{\mathrm{A}}=-0.289$, $\theta_{\mathrm{W}}=-0.205, \theta_{\mathrm{E}}=-0.004$ and $\theta_{\mathrm{N}}=0.055$ (we also note that the precision of the calibration was left at the third decimal as likelihood values started to plateau). The elongated shape of the likelihood dependencies between two parameters indicate some correlation between the parameters (Fig. 1). When we examine the parameter combinations with highest likelihoods (top 250 values), the strongest correlations $(\approx 0.77)$ are present between $\theta_{\mathrm{A}}$ and $\theta_{\mathrm{W}}, \theta_{\mathrm{A}}$ and $\theta_{\mathrm{N}}$ as well as $\theta_{\mathrm{W}}$ and $\theta_{\mathrm{N}}$.
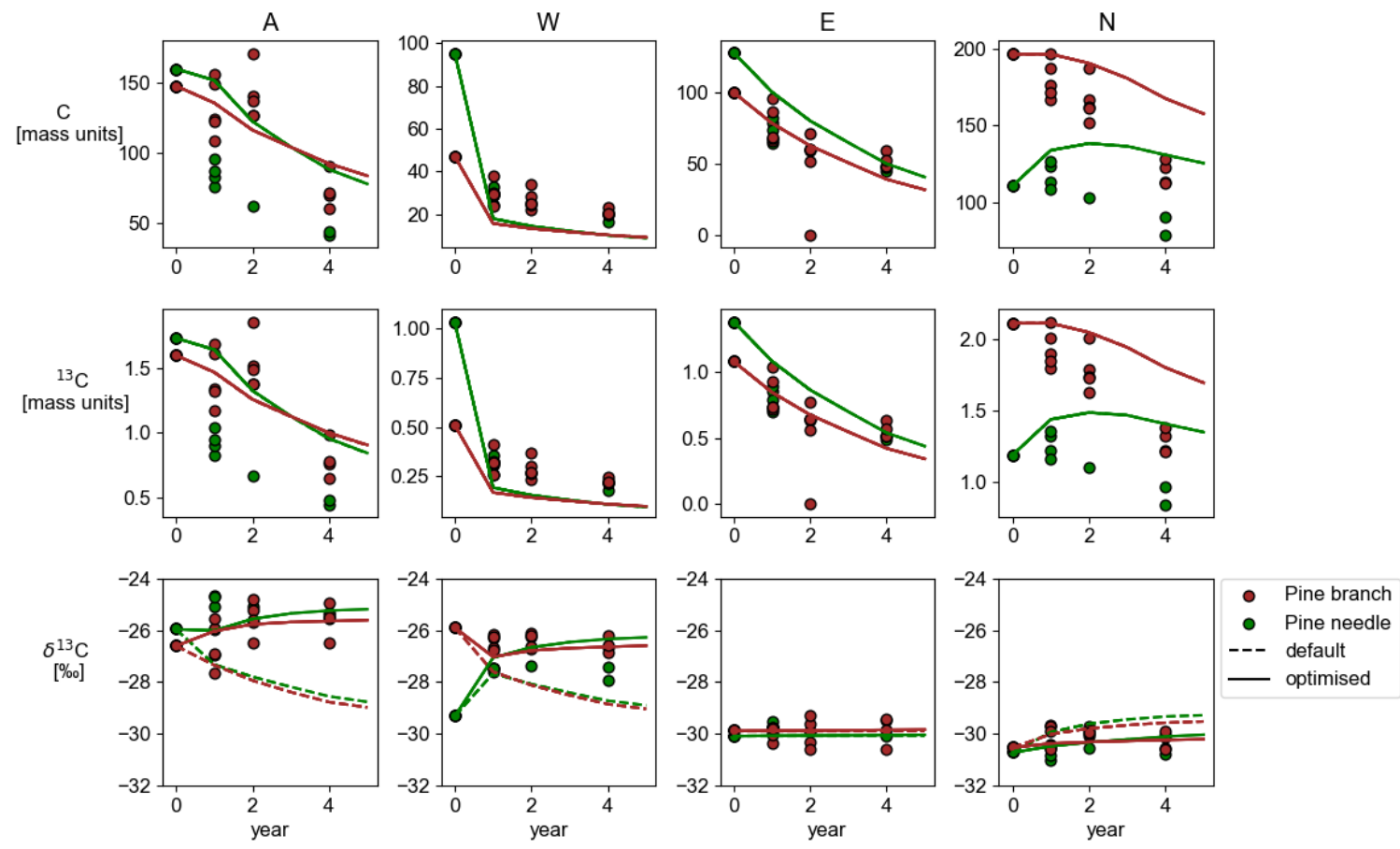

Figure 2. Shown are timeseries produced by the default and optimised Yasso model versions for the different AWEN pools together with assimilated observations. The model results for $\mathrm{C}$ and ${ }^{13} \mathrm{C}$ concentrations are on top of each other.

The default and optimised parameter values were used to generate SOM decomposition and related $\mathrm{C},{ }^{13} \mathrm{C}$ and $\delta^{13} \mathrm{C}$ timeseries from the given initial states (Fig. 2). The differences between the simulated ${ }^{13} \mathrm{C}$ concentrations are too small to be evident ( $\mathrm{C}$ concentrations are identical), but we get a clear signal from the $\delta^{13} \mathrm{C}$ values. Overall, both model versions tend to underestimate the speed of SOM decomposition (the $\mathrm{C}$ and ${ }^{13} \mathrm{C}$ concentrations) at Lakkasuo for $\mathrm{A}$ and $\mathrm{N}$ pools and overestimate for $\mathrm{W}$ pool. The default Yasso model is reducing the relative ${ }^{13} \mathrm{C}$ content (reducing the $\delta^{13} \mathrm{C}$ values) for $\mathrm{A}$ and $\mathrm{W}$ pools and deviating from the observations whereas the optimised model version seems to be increasing the relative ${ }^{13} \mathrm{C}$ content and 
following the observations more closely. There is no apparent difference for the E pool, but the calibration has lowered the rate of ${ }^{13} \mathrm{C}$ enrichment for the $\mathrm{N}$ pool. We have calculated and gathered the mean and standard deviation of the corresponding pointwise $\delta^{13} \mathrm{C}$ model bias values (model - observations) for the individual AWEN pools to Table 1.

Table 1. Calculated default and optimised model bias (model - observations) mean and standard deviation for the different AWEN pools.

\begin{tabular}{rcccccccc} 
& \multicolumn{2}{c}{$\mathrm{A}-\delta^{13} \mathrm{C}$} & \multicolumn{2}{c}{$\mathrm{W}-\delta^{13} \mathrm{C}$} & \multicolumn{2}{c}{$\mathrm{E}-\delta^{13} \mathrm{C}$} & \multicolumn{2}{c}{$\mathrm{N}-\delta^{13} \mathrm{C}$} \\
& $\mu$ & $\sigma$ & $\mu$ & $\sigma$ & $\mu$ & $\sigma$ & $\mu$ & $\sigma$ \\
\hline default & -2.2 & 1.05 & -1.29 & 0.74 & -0.07 & 0.36 & 0.47 & 0.49 \\
optimised & -0.102 & 0.76 & -0.003 & 0.63 & -0.04 & 0.37 & -0.08 & 0.4 \\
\hline
\end{tabular}

The Lakkasuo initial states and generated average year (averaged monthly temperature and annual precipitation) from years 2000-2014 were used to simulate a 50-year long carbon decomposition (Fig. 3). This simulation can be compared to Lakkasuo peat column $\delta^{13} \mathrm{C}$ values at different depths (Hilasvuori et al., 2013, Table 2) that we have naively equated to the simulation at regular 10-year intervals. The holocellulose values are comparable to the A pool, Klason to the $\mathrm{N}$ pool, nonpolar extracts to the E pool and polar extracts to the W pool. A noteworthy detail is that on short term (Fig. 2) the default model increased the relative ${ }^{13} \mathrm{C}$ content $\left(\delta^{13} \mathrm{C}\right.$ values) of $\mathrm{E}$ and $\mathrm{N}$ more than the optimised version, but on longer timescale this situation is reversed for $\mathrm{E}$ and projected to reverse for $\mathrm{N}$ (Fig. 3).
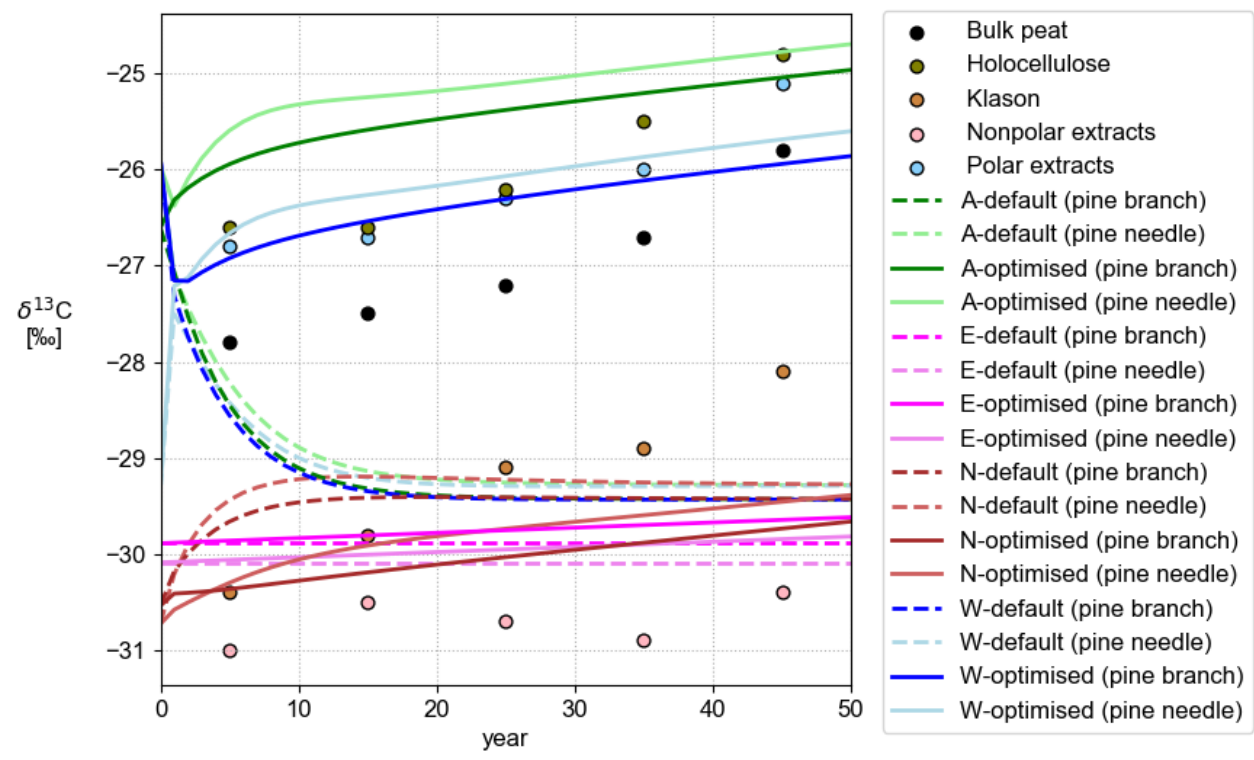

Figure 3. Timeseries of simulated $\delta^{13} \mathrm{C}$ values of the different AWEN pools for the default and optimised Yasso model versions. Scatterplotted are peat column composition $\delta^{13} \mathrm{C}$ values (Hilasvuori et al., 2013, Table 2) at different depths. 
We have introduced simple modifications to the Yasso model in order to account for ${ }^{13} \mathrm{C}-\mathrm{SOM}$ decomposition. Incorporation of $\delta^{13} \mathrm{C}$ on SOM decomposition models is a necessary step towards integration of Earth system and dynamic land ecosystem models. The $\delta^{13} \mathrm{C}$ values of different organic compounds or chemical fractions of mixed organic material can be used as natural tracers which provide a unique tool to investigate and uncover complex decomposition processes in soil.

In the current study, we introduced new $\theta$ parameters to account for ${ }^{13} \mathrm{C}-\mathrm{SOM}$ decomposition in the Yasso model. The calibration of these parameters only depend on the $\delta^{13} \mathrm{C}$ values, i.e. the relative carbon isotope concentrations, and revealed unimodal distributions for all four AWEN pool related parameters. Considering the acquired optima and taking into account that generally the ratio ${ }^{13} \mathrm{C} /{ }^{12} \mathrm{C} \approx 0.01$, then the new ${ }^{13} \mathrm{C}$-SOM decomposition utilises values that differ at maximum $3 \%$ (for $\theta_{\mathrm{A}}$ ) from the default decomposition parameter values. Therefore, it is not surprising that both default and optimised model versions generate nearly identical SOM decomposition both on a short (Fig. 2) and long term (we did not provide this image as it provides no additional value).

The acquired optima for $\theta_{\mathrm{A}}, \theta_{\mathrm{E}}$ and $\theta_{\mathrm{W}}$ are all negative, which in the model translates to reduced ${ }^{13} \mathrm{C}$-SOM decomposition rate (Fig. 2). Likewise, the positive value for $\theta_{\mathrm{N}}$ implies increased ${ }^{13} \mathrm{C}-\mathrm{SOM}$ decomposition when compared to the default model. However, the reduction in $\delta^{13} \mathrm{C}$ values, when compared to the default model version, is only true on shorter timescales (Fig. 2) as each pool has a clear trend to increase relative ${ }^{13} \mathrm{C}$ content during the 50 -year long simulation (Fig. 3). This is due to the reduced ${ }^{13} \mathrm{C}$-SOM decomposition in other pools - as there is more ${ }^{13} \mathrm{C}$ present in these pools, there is more ${ }^{13} \mathrm{C}$ available to be transported into the $\mathrm{N}$ pool, which compensates for the increased decomposition. This situation is not ideal, but understandable as Yasso also operates in the terms of "bulk" soil - there are no soil layers or differences in the effects of temperature, precipitation or Q10 at different soil depths (see e.g. Fig. 1 in Hilasvuori et al. (2013)).

The straightforward changes to the Yasso model have improved the model capabilities in reproducing observed $\delta^{13} \mathrm{C}$ values in short (Fig. 2) and longer timescales (Fig. 3). Results from the 50-year long simulation seem to corroborate the initial hypothesis for $\mathrm{A}, \mathrm{W}$ and $\mathrm{N}$ pools that the relative ${ }^{13} \mathrm{C}$ content in soil (larger $\delta^{13} \mathrm{C}$ values) increases with time. The optimised model even yields a positive trend for $\mathrm{E}$ pool $\delta^{13} \mathrm{C}$ whereas the default model tends to converge the $\delta^{13} \mathrm{C}$ values of all pools to roughly -30. The peat decomposition at different depths (Hilasvuori et al., 2013, Table 2) can be naively approximated to be of different ages at 10-year intervals. The optimised model behaviour follows the trend of these measurements and the results are highly encouraging, even though the model is driven with a single averaged year representing the meteorological conditions from the beginning of the 21 st century.

As estimation and modelling of soil organic matter decomposition, but also $\mathrm{C}$ sequestration, are current scientific challenges, our modified model demonstrates how measurable delta-13 values can be used to improve SOM decomposition model accuracy and predictability. The required model modifications were straightforward and resulted in drastic improvement of modelled $\delta^{13} \mathrm{C}$ values of SOM extracts. Although we emphasize the preliminary nature of our results due to limited calibration dataset, we foresee the model to act as a truly important tool to understand the role of isotopic fingerprints within soil carbon decomposition. The Yasso-C13 model should be tested and parameters evaluated using larger $\delta^{13} \mathrm{C}$ datasets that are rather 
https://doi.org/10.5194/bg-2021-327

Preprint. Discussion started: 23 December 2021

(c) Author(s) 2021. CC BY 4.0 License.

(c) (i)

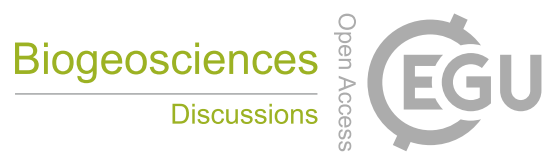

straightforward to produce, or meta-analysis using literature-based values could be also used for further evaluation across varying scales (local, regional, global).

\section{Conclusions}

We have demonstrated how to incorporate ${ }^{13} \mathrm{C}$-SOM decomposition into the Yasso model and calibrate it. The model modifications were simple and straightforward and resulted in greatly improved simulated $\delta^{13} \mathrm{C}$ values. The capability of a model to simulate soil ${ }^{13} \mathrm{C}$ content and to better simulate SOM decomposition improves the applicability of Yasso-C13 model to scale process from ecosystem level to regional and global using $\delta^{13} \mathrm{C}$ as a tracer. Conceptually the presented work is on solid ground, but the lack of suitable calibration and validation data urges further studies that produce new, precise experimental $\delta^{13} \mathrm{C}$ data suitable for Yasso-C13 model calibration and validation. Likewise further efforts should be made to include soil layers into the Yasso model.

Code and data availability. The data required to reproduce the results is available at Zenodo portal (Mäkelä, 2021a). The Yasso model source code and R interface are also available at Zenodo (Mäkelä, 2021b) or as "C13" branch at https://github.com/YASSOmodel/Ryassofortran. 
https://doi.org/10.5194/bg-2021-327

Preprint. Discussion started: 23 December 2021

(c) Author(s) 2021. CC BY 4.0 License.

(c) (i)

\section{Appendix A: Yasso model parameters}

Table A1. Utilised Yasso model parameter values.

\begin{tabular}{|c|c|c|}
\hline Description & Parameter & Value \\
\hline Base decomposition rate for A pool & $\alpha_{A}$ & 0.51 \\
\hline Base decomposition rate for $\mathrm{W}$ pool & $\alpha_{W}$ & 5.19 \\
\hline Base decomposition rate for $\mathrm{E}$ pool & $\alpha_{E}$ & 0.13 \\
\hline Base decomposition rate for $\mathrm{N}$ pool & $\alpha_{N}$ & 0.1 \\
\hline Mass transfer fraction from $\mathrm{W}$ to $\mathrm{A}$ & $p_{W A}$ & 0.5 \\
\hline Mass transfer fraction from $\mathrm{E}$ to $\mathrm{A}$ & $p_{E A}$ & 0 \\
\hline Mass transfer fraction from $\mathrm{N}$ to $\mathrm{A}$ & $p_{N A}$ & 1.0 \\
\hline Mass transfer fraction from $\mathrm{A}$ to $\mathrm{W}$ & $p_{A W}$ & 1.0 \\
\hline Mass transfer fraction from $\mathrm{E}$ to $\mathrm{W}$ & $p_{E W}$ & 0.99 \\
\hline Mass transfer fraction from $\mathrm{N}$ to $\mathrm{W}$ & $p_{N W}$ & 0 \\
\hline Mass transfer fraction from $\mathrm{A}$ to $\mathrm{E}$ & $p_{A E}$ & 0 \\
\hline Mass transfer fraction from $\mathrm{W}$ to $\mathrm{E}$ & $p_{W E}$ & 0 \\
\hline Mass transfer fraction from $\mathrm{N}$ to $\mathrm{E}$ & $p_{N E}$ & 0 \\
\hline Mass transfer fraction from $\mathrm{A}$ to $\mathrm{N}$ & $p_{A N}$ & 0 \\
\hline Mass transfer fraction from $\mathrm{W}$ to $\mathrm{N}$ & $p_{W N}$ & 0.163 \\
\hline Mass transfer fraction from $\mathrm{E}$ to $\mathrm{N}$ & $p_{E N}$ & 0 \\
\hline First order temperature impact parameter for AWE & $a_{A W E}$ & 0.158 \\
\hline Second order temperature impact parameter for AWE & $b_{A W E}$ & $-2.0 \times 10^{-3}$ \\
\hline First order temperature impact parameter for $\mathrm{N}$ & $a_{N}$ & 0.17 \\
\hline Second order temperature impact parameter for $\mathrm{N}$ & $b_{N}$ & $-5.0 \times 10^{-3}$ \\
\hline First order temperature impact parameter for $\mathrm{H}$ & $a_{H}$ & 0.067 \\
\hline Second order temperature impact parameter for $\mathrm{H}$ & $b_{H}$ & 0 \\
\hline Precipitation impact parameter for AWE & $g$ & -1.44 \\
\hline Precipitation impact parameter for $\mathrm{N}$ & $g_{N}$ & -2.0 \\
\hline
\end{tabular}

Author contributions. JM was responsible for the model modifications, simulations and preparing the manuscript with JH, JL and TV contributing to the experiment design. LA was responsible for the ${ }^{13} \mathrm{C}$ analysis and HF for the AWEN extractions. MO provided premises and equipment for the isotopic measurements. With especial thanks to Anneli Rautiainen for the work on AWEN extractions and Hanna Turunen and Igor Shevchuk for stable isotopic sample preparation and measurement. 
https://doi.org/10.5194/bg-2021-327

Preprint. Discussion started: 23 December 2021

(C) Author(s) 2021. CC BY 4.0 License.

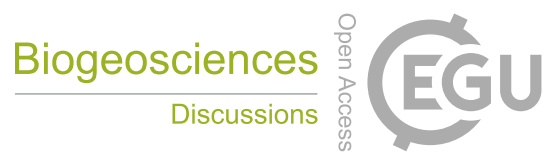

Competing interests. The authors declare that they have no competing interests.

Acknowledgements. This research has been funded by the Strategic Research Council at the Academy of Finland (MULTA, decision no 327214) and the Academy of Finland Flagship Program (ACCC, decision no 337552). This study was additionally supported by Finnish Academy of Science (ACCUSOIL, project no 297350). 
https://doi.org/10.5194/bg-2021-327

Preprint. Discussion started: 23 December 2021

(c) Author(s) 2021. CC BY 4.0 License.

(c) (i)

Acharya, B. S., Rasmussen, J., and Eriksen, J.: Grassland carbon sequestration and emissions following cultivation in a mixed crop rotation, Agr. Ecosyst. Environ., 153, 33-39, https://doi.org/10.1016/j.agee.2012.03.00, 2012.

Craig, H.: Isotopic standards for carbon and oxygen and correction factors for mass-spectrometric analysis of carbon dioxide, Geochim. Cosmochim. Ac., 12, 133-149, https://doi.org/10.1016/0016-7037(57)90024-8, 1957.

Flanagan, L., Ehleringer, J., and Pataki, D., eds.: Stable isotopes and biosphere-atmosphere interactions, Elsevier, https://doi.org/10.1016/B978-0-12-088447-6.X5000-4, 2005.

Fry, B.: Stable isotope Ecology, Springer, first edn., https://doi.org/10.1007/0-387-33745-8, 2006.

Heikkinen, J., Keskinen, R., Regina, K., Honkanen, H., and Nuutinen, V.: Estimation of carbon stocks in boreal cropland soils - methodological considerations, Eur. J. Soil Sci., pp. 1-12, https://doi.org/10.1111/ejss.13033, 2020.

Hilasvuori, E., Akujärvi, A., Fritze, H., Karhu, K., Laiho, R., Mäkiranta, P., Oinonen, M., Palonen, V., Vanhala, P., and Liski, J.: Temperature sensitivity of decomposition in a peat, Soil Biol. Biochem., 67, 47-54, https://doi.org/10.1016/j.soilbio.2013.08.009, 2013.

Kolari, P., Kulmala, L., Pumpanen, J., Launiainen, S., Ilvesniemi, H., Hari, P., and Nikinmaa, E.: $\mathrm{CO}_{2}$ exchange and component $\mathrm{CO}_{2}$ fluxes of a boreal Scots pine forest, Boreal Environ. Res., 14, 761-783, http://www.borenv.net/BER/pdfs/ber14/ber14-761.pdf, 2009.

Liski, J., Palosuo, T., Peltoniemi, M., and Sievänen, R.: Carbon and decomposition model Yasso for forest soil, Ecol. Model., 189, 168-182, https://doi.org/10.1016/j.ecolmodel.2005.03.005, 2005.

Mäkelä, J.: Lakkasuo carbon isotope and AWEN extraction data for Yasso-C13 model development [Data set], Zenodo, https://doi.org/10.5281/zenodo.5095079, 2021a.

Mäkelä, J.: Ryassofortran with C13 [Model source code], Zenodo, https://doi.org/10.5281/zenodo.4468521, 2021 b.

Poeplau, C., Don, A., Six, J., Kaiser, M., Benbi, D., Chenu, C., Cotrufo, M. F., Derrien, D., Gioacchini, P., Grand, S., Gregorich, E., Griepentrog, M., Gunina, A., Haddix, M., Kuzyakov, Y., Kühnel, A., Macdonald, L. M., Soong, J., Trigalet, S., Vermeire, M.L., Rovira, P., van Wesemael, B., Wiesmeier, M., Yeasmin, S., Yevdokimov, I., and Nieder, R.: Isolating organic carbon fractions with varying turnover rates in temperate agricultural soils - A comprehensive method comparison, Soil Biol. Biochem., 125, 10-26, https://doi.org/10.1016/j.soilbio.2018.06.025, 2018.

Smith, P., Soussana, J.-F., Angers, D., Schipper, L., Chenu, C., Rasse, D. P., Batjes, N. H., van Egmond, F., McNeill, S., Kuhnert, M., Arias-Navarro, C., Olesen, J. E., Chirinda, N., Fornara, D., Wollenberg, E., Álvaro Fuentes, J., Sanz-Cobena, A., and Klumpp, K.: How to measure, report and verify soil carbon change to realize the potential of soil carbon sequestration for atmospheric greenhouse gas removal, Glob. Change Biol., 26, 2190-241, https://doi.org/10.1111/gcb.14815, 2020.

Straková, P., Anttila, J., Spetz, P., Kitunen, V., Tapanila, T., and Laiho, R.: Litter quality and its response to water level drawdown in boreal peatlands at plant species and community level, Plant Soil, 335, 501-520, https://doi.org/10.1007/s11104-010-0447-6, 2010.

Straková, P., Niemi, R. M., Freeman, C., Peltoniemi, K., Toberman, H., Heiskanen, I., Fritze, H., and Laiho, R.: Litter type affects the activity of aerobic decomposers in a boreal peatland more than site nutrient and water table regimes, Biogeosciences, 8, 2741-2755, https://doi.org/10.5194/bg-8-2741-2011, 2011.

Straková, P., Penttilä, T., Laine, J., and Laiho, R.: Disentangling direct and indirect effects of water table drawdown on above- and belowground plant litter decomposition: consequences for accumulation of organic matter in boreal peatlands, Glob. Change Biol., 18, 322-335, https://doi.org/10.1111/j.1365-2486.2011.02503.x, 2012. 
https://doi.org/10.5194/bg-2021-327

Preprint. Discussion started: 23 December 2021

(c) Author(s) 2021. CC BY 4.0 License.

(c) (1)

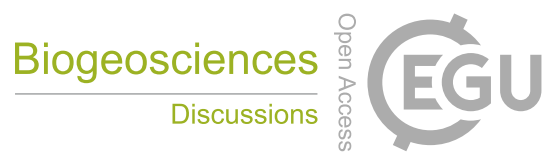

Triberti, L., Nastri, A., and Baldoni, G.: Long-term effects of crop rotation, manure and mineral fertilisation on carbon sequestration and soil fertility, Eur. J. Agron., 74, 47-55, https://doi.org/10.1016/j.eja.2015.11, 2016.

Tuomi, M., Laiho, R., Repo, A., and Liski, J.: Wood decomposition model for boreal forests, Ecol. Model., 222, 709-718, https://doi.org/10.1016/j.ecolmodel.2010.10.025, 2011.

245 Viskari, T., Laine, M., Kulmala, L., Mäkela, J., Fer, I., and Liski, J.: Improving Yasso15 soil carbon model estimates with ensemble adjustment Kalman filter state data assimilation, Geosci. Model Dev., 13, 5959-5971, https://doi.org/10.5194/gmd-13-5959-2020, 2020.

Viskari, T., Pusa, J., Fer, I., Repo, A., Vira, J., and Liski, J.: The impact of calibrating soil organic carbon model Yasso with multiple datasets, Geosci. Model Dev. Discuss., in review, 1-36, https://doi.org/10.5194/gmd-2021-273, 2021.

Wilman, E. A.: Carbon Sequestration in Agricultural Soils, J. Agr. Resour. Econ., 36, 1-18, https://doi.org/10.22004/ag.econ.105535, 2011. 